\title{
CHA UCER.
}

\section{STUDIEN}

\section{ZUR GESCHICHTE SEINER ENTWICKLUNG}

UND

ZUR CHRONOLOGIE SEINER SCHRIFTEN

voN

\section{BERNHARD TEN BRINK.}

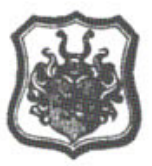

E R $\mathbf{S}$ T R T H E I L.

MUYNSTER.

ADOLPH RUSSELL'S VERLAG.

1870. 



\section{HERRN PROFESSOR}

\section{NICOLAUS DELIUS}

IN DANKBARER VEREHRUNG. 
